\title{
Land-Use Change and Health Risks in the Process of Urbanization: A Spatiotemporal Interpretation of a Typical Case in Changzhou, China
}

\author{
Dongyang Yang ${ }^{1}\left(\mathbb{D}\right.$, Chao $\mathrm{Ye}^{2, *(\mathbb{D})}$ and Jianhua $\mathrm{Xu}{ }^{2,3} \mathbb{C}$ \\ 1 Key Research Institute of Yellow River Civilization and Sustainable Development \& Collaborative Innovation \\ Center on Yellow River Civilization, Henan University, Kaifeng 475004, China; yangdy@lreis.ac.cn \\ 2 School of Geographic Sciences \& Institute of Eco-Chongming, East China Normal University, \\ Shanghai 200241, China; jhxu@geo.ecnu.edu.cn \\ 3 Research Center for East-West Cooperation in China, East China Normal University, Shanghai 200241, China \\ * Correspondence: cye@geo.ecnu.edu.cn
}

check for updates

Citation: Yang, D.; Ye, C.; Xu, J. Land-Use Change and Health Risks in the Process of Urbanization: A Spatiotemporal Interpretation of a Typical Case in Changzhou, China. Land 2021, 10, 820. https:// doi.org/10.3390/land10080820

Academic Editor: Shiliang Su

Received: 2 July 2021

Accepted: 3 August 2021

Published: 5 August 2021

Publisher's Note: MDPI stays neutral with regard to jurisdictional claims in published maps and institutional affiliations.

Copyright: (c) 2021 by the authors. Licensee MDPI, Basel, Switzerland. This article is an open access article distributed under the terms and conditions of the Creative Commons Attribution (CC BY) license (https:// creativecommons.org/licenses/by/ $4.0 /)$.

\begin{abstract}
China has undergone rapid urban expansion in recent decades. At the same time, environmental pollution and its risk to public health have increased. However, the relationship between urban land-use changes and health is ambiguous and insufficiently understood. Based on a typical city-scale case-namely, Changzhou, China - this research aimed to interpret the evolution of health risks alongside land-use change during the process of urbanization. We gathered data from multiple sources, including population mortality data, socioeconomic data, remote-sensing images, data for the points of interest of enterprises, and relevant information on environmental health events and cancers. The results showed that Changzhou's urbanization was typical insofar as it was characterized by massive growth in industry, a rapid increase in the urban population, and urban land expansion. Health risks related to environmental pollution increased considerably with urban land expansion over time, and they increased with proximity to the pollution. The results from a generalized linear model confirmed that Changzhou's urbanization triggered increasing health risks. Our study interpreted the relationship between urban land expansion and health risks from a spatiotemporal perspective. It can be used as a reference for urban planning and policymaking with regard to urban environmental health.
\end{abstract}

Keywords: land use change; urbanization; environmental pollution; health risks

\section{Introduction}

Morbidity and mortality from chronic diseases related to environmental pollution are increasing alongside urbanization in China [1,2]. Urbanization is a spatiotemporal process by which urban components are transformed. These components include land use, industry, population, and many other natural and socioeconomic factors within the urban territorial system. These transitions inevitably affect public health. In this regard, there is an urgent need to understand the relationship between urban land expansion, urbanization, and environmental health issues in China.

In recent decades, China has seen unparalleled speed in rural-urban transition. The urban population rose from 191 million in 1980 to 831 million in 2018, and the urbanization rate reached 59.58\% [3]. In general, urbanization improves living conditions, including education, employment, services, income, and health [4]. However, unplanned urban expansion often causes environmental hazards and health risks within the developing world [5-7]. China's urbanization, both historical and present, was accompanied by the process of industrialization. With rapid growth in industrialization, China's urbanization led to widespread environmental pollution and damage, especially in terms of land pollution and degradation [8-10]. Decommissioned industrial sites and current industrial 
parks have contaminated and seriously deteriorated the land [11,12]. The fast pace of urban development left little time for careful planning and design. Having experienced 30 years of rapid growth and urbanization, China now faces unique environmental health challenges $[13,14]$.

There are numerous studies on environmental health issues caused by urbanization $[2,13,15]$. Different aspects of urban living, including income, healthcare, and education, were considered determinants that might affect public health [15-17]. In particular, environmental pollution has long been identified as a major risk factor $[2,18,19]$. Brownfields and industry parks often use hazardous substances and pollutants, and these have been a major concern of researchers [20-26]. Many studies have focused on pollution exposure and health risk assessments based on environmental pollution around brownfields and industry parks [22,27-29]. Simultaneously, scholars have documented that the proportion of mortality caused by chronic diseases and cancer increased obviously in urban China [30], and chronic disease incidence rates were higher in big cities than in small cities and rural areas in China [13]. Meanwhile, the dynamic changes in health risks during the urbanization process and the evolutionary relationship between urbanization, urban land change and health risks has rarely been studied, especially at the scale of a city. Hence, there is a need to adopt a spatiotemporal perspective to urbanization in order to understand environmental health issues in China.

Urbanization is a dynamic spatiotemporal process during which natural and human factors radically change from rural to urban. Different patterns of urbanization differ in how quickly they develop, and with regard to their effects on land and public health. Considering the spatiotemporal transformations of urban components-including land use, industry, and population -we offer an interpretation of the relationship between land-use change and health issues in Changzhou, China. In what follows, we present our findings and discuss policy implications. We expect that our results will contribute to effective policymaking regarding urbanization in order to abate urban land pollution and health risks for the sake of urban sustainability.

\section{Materials and Methods}

\subsection{Study Area}

Changzhou, located on the southern bank of the Yangtze River, is a prefecture-level city in southern China's Jiangsu province. Changzhou borders the provincial capital of Nanjing to the west, Zhenjiang to the northwest, Wuxi to the east, and Zhejiang province to the south (Figure 1). Changzhou is part of the highly developed Yangtze Delta region of China, extending northwest from Shanghai. In 2018, its total population was 4.74 million, and its urban population was 3.85 million. The urbanization rate reached $73.3 \%, 13.72 \%$ higher than the average in China.

Data published by the Ministry of Environmental Protection of China show that most chemical and petrochemical construction projects are distributed near rivers and lakes in highly populated areas [31]. Changzhou is located in the Yangtze River Delta close to many water bodies and dense populations. It also has a large chemical industry, with hazardous chemical substances.

\subsection{Multi-Source Data}

We gathered data on Changzhou from multiple sources: population mortality data, socioeconomic data, point-of-interest (POI) data, remote-sensing images, and high-resolution images. The population mortality data (from 2001 to 2015) and the socioeconomic data, including data on demographics, economy development, and pollution emissions, were obtained from the Changzhou Statistical Yearbook (from 1990 to 2015) on China National Knowledge Infrastructure (http://tongji.cnki.net/). The urbanization rate was calculated as the proportion of urban population in the total population. The POI data were obtained from Baidu Maps (http:/ /map.baidu.com/). Given that thermal power, steel, cement, petrifaction, chemical engineering, non-ferrous smelting, textile, and paper-making are 
high-polluting industries, the POI data for these industries were extracted. Remote-sensing images (Landsat TM and OLI_TIRS) from 1995 and 2015 were downloaded from the Geospatial Data Cloud (http://www.gscloud.cn/). Data on cancer were gathered from published literature [32-37]. In addition, national and local authoritative media have reported massive environmental health events in Changzhou. A briefing on these data and their sources is presented in Table 1. Relevant information, such as the type and location of these events, was collected from the reports and verified through a field survey.

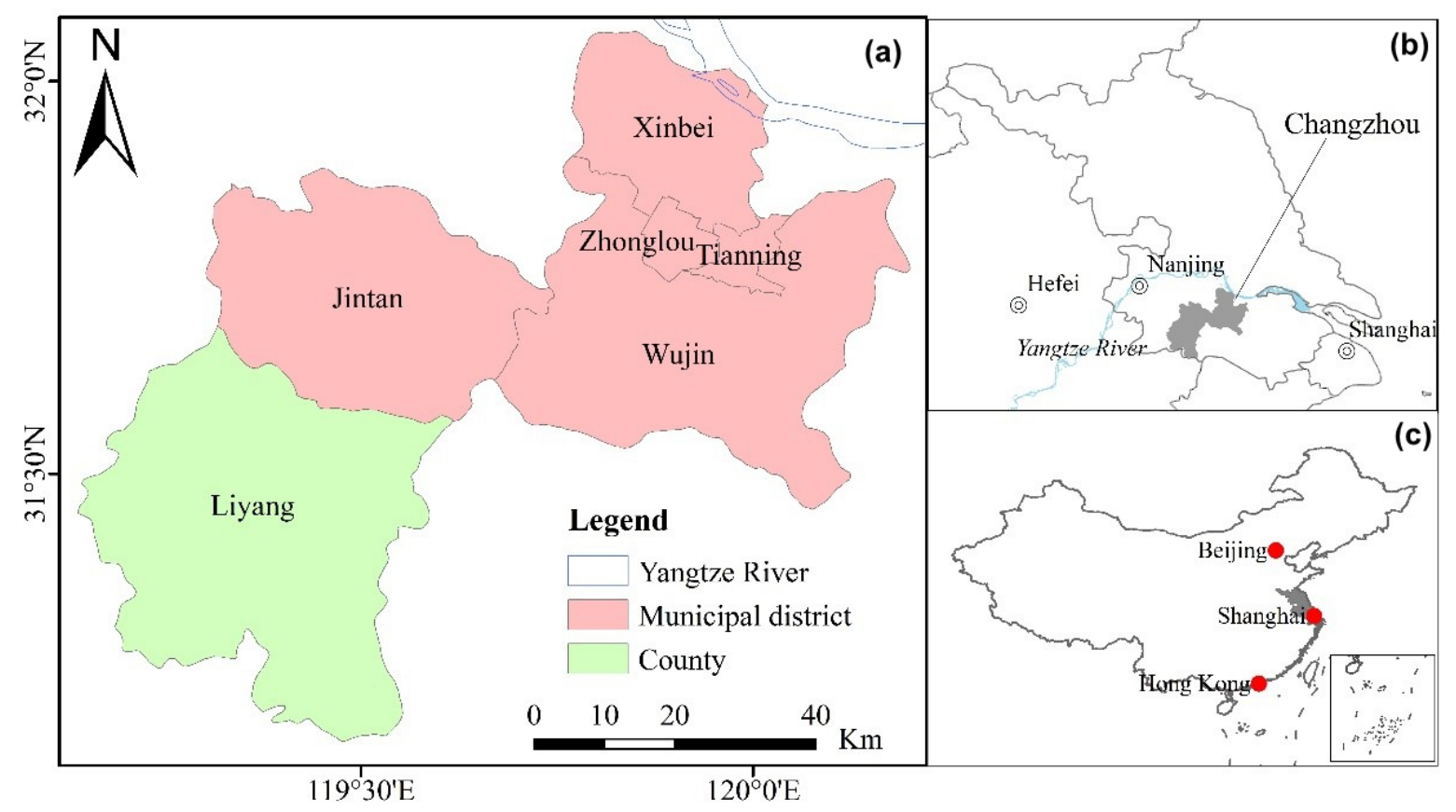

Figure 1. Study region (a) and its location in Jiangsu (b) and China (c).

Table 1. Data and sources.

\begin{tabular}{cc}
\hline Data & Source \\
\hline Population mortality data & Changzhou Statistical Yearbook \\
Socio-economic data & Changzhou Statistical Yearbook \\
POI & Baidu map \\
Remote-sensing images & Geospatial Data Cloud \\
High-resolution images & Baidu map \\
Cancer data & Published literature [32-37] \\
\hline
\end{tabular}

Construction land in 1995 and 2015 was interpreted based on remote-sensing images, and the spatial distribution and time variation of the newly increased construction areas and enterprises could be examined by applying overlay analysis and point density analysis using ArcGIS software. Environmental health events with locations were mapped to show their spatial distribution.

\subsection{Linear Weighting Method}

To measure the comprehensive pollution from three major industrial polluting sourceswastewater, waste gas, and solid waste-we used the linear weighting method to calculate the comprehensive pollution index $(F)$ based on data for pollution emissions:

$$
F_{i}=\sum_{j=1}^{n} x_{i j} \times w_{j}
$$


where $x_{i j}$ is the normalized value of polluting emission $j$ in year $i$, and $w_{j}$ represents the weight of polluting emission $j$, calculated as follows:

$$
w_{j}=\frac{\sigma_{j}}{\sum_{j=1}^{n} \sigma_{j}}
$$

where $\sigma$ is the standard deviation of observations $x_{i j}$.

\subsection{Bivariate Spatial Association}

Lee (2001) developed a bivariate spatial association based on univariate spatial correlation analysis to examine the spatial association between bivariate observations [38]. The bivariate spatial association is defined as follows:

$$
I_{k l}^{i}=Z_{k}^{i} \sum_{j=l}^{n} W_{i j} Z_{l}^{i}
$$

where $W_{i j}$ denotes the spatial weight matrix, $Z_{k}^{i}=\left[x_{k}^{i}-\overline{x_{k}}\right] / \sigma_{k}, Z_{k}^{i}=\left[x_{k}^{j}-\overline{x_{l}}\right] / \sigma_{l}, x_{k}^{i}$ is the observation $k$ at location $i, x_{l}^{j}$ is the observation $l$ at location $j$, and $\sigma_{k}$ and $\sigma_{l}$ denote the variance of $x_{k}$ and $x_{l}$, respectively.

As with spatial correlation analysis, the bivariate spatial association visualizes the results using a Moran's I scatterplot and the bivariate LISA cluster map [39]. We used this method to examine the spatial association between newly increased construction land and newly increased polluting enterprises.

\subsection{Generalized Additive Model (GAM)}

Health outcomes can exhibit linear or nonlinear variation, as can urbanization, landuse expansion, and industrial development. The GAM model provides primary functions (linear, polynomial, or spline) to fit the variation of dependent variables [40], such as health outcomes, and independent variables. Given the complexity of the relationship between urbanization and environmental health, we constructed the following GAM model:

$$
Y=\beta_{0}+\sum_{j=1} f_{j}\left(X_{j}\right)+\epsilon_{j}
$$

where $Y$ is a dependent variable (such as total mortality), $f_{j}(\cdot)$ is a random univariate function for independent variable $X_{j}$ (such as the urbanization rate), and $\epsilon_{j}$ is a normal random error term.

The model determines the relationships between the dependent variable and independent variable according to the degree of freedom (DF): if $D F=1$, the relationship is linear; if $\mathrm{DF}>1$, the relationship is nonlinear; and a higher DF indicates a more significant nonlinear relationship.

We included the urbanization rate (UR, the percentage of the urban population in the total population), the construction land area (CLA, $\left.\mathrm{km}^{2}\right)$, and the proportion of heavy industrial output to total industrial output (PHI, \%) as independent variables. We included total mortality (2001-2015), the number of cancer cases (2002-2011), and the mortality from cancer from 2009-2015 in Changzhou as dependent variables into the GAM, to explore the relationship between urbanization and health risks. Mortality from cancer in 2009 and 2010 was estimated according to its linear relationship with that of Wujin district, with a $\mathrm{R}^{2}$ of 0.98 . 


\section{Results}

3.1. Temporal Interpretation of Land-Use Change and Environmental Health Risks in Changzhou 3.1.1. Evolution of Urbanization and Land Use

In the past decades, Changzhou experienced rapid urbanization (Figure 2). In 2003, the urbanization rate (the proportion of the urban population) was $56.45 \%$. In 2018 , it reached $72.5 \%$. The built-up area also increased rapidly during the period. The built-up area was $92.28 \mathrm{~km}^{2}$ in 2003, and $300 \mathrm{~km}^{2}$ in 2018. There was massive growth in industrial land along with Changzhou's urban expansion: the industrial land area increased from $25.91 \mathrm{~km}^{2}$ to $95.64 \mathrm{~km}^{2}$ during the study period, with a growth rate of $269.12 \%$ (Figure 2).

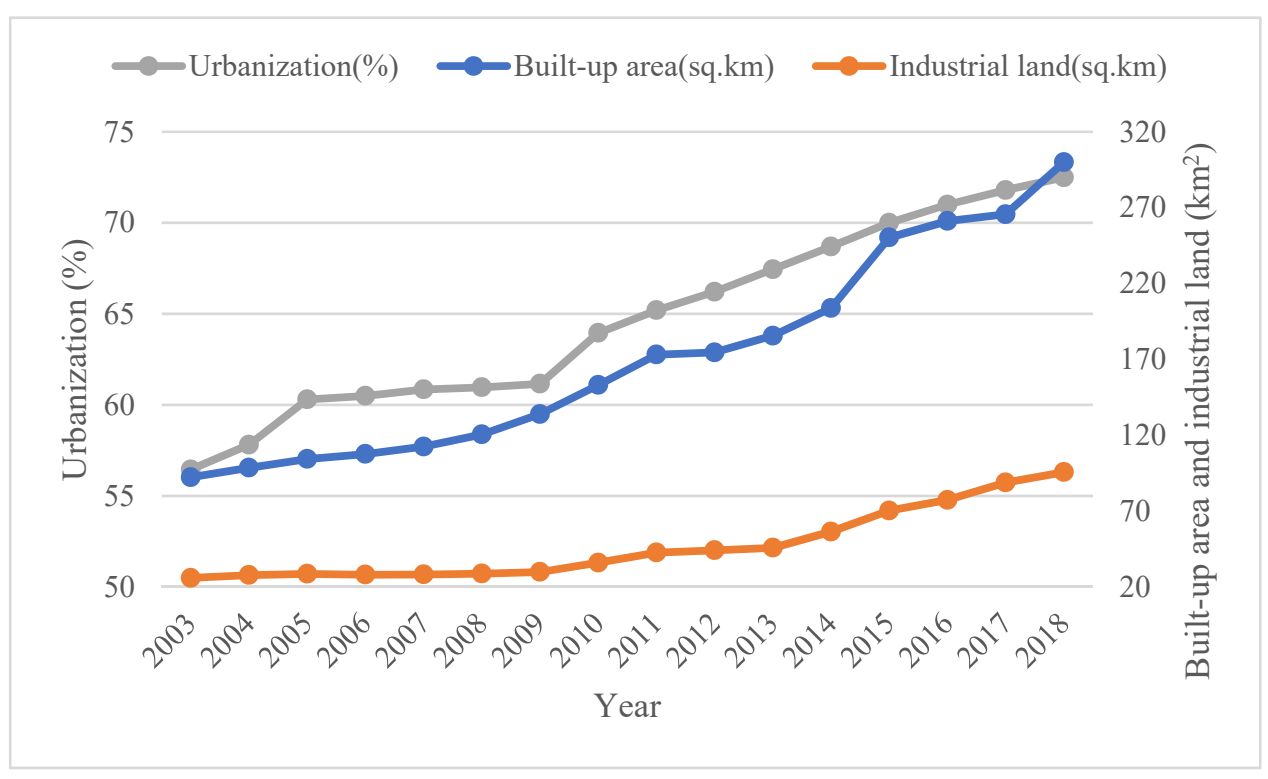

Figure 2. Urbanization evolution and land use change of Changzhou from 2003 to 2018.

\subsubsection{Evolution of Population and Pollution}

However, Changzhou's urbanization had a profound effect on the environment. Figure 3 shows that the pollution index - calculated using the linear weighting method based on the three industrial waste sources, namely, waste gas, wastewater, and waste solids-increased from 0.13 to 0.66 , indicating that pollution emissions increased greatly from 1990 to 2015 (Figure 3). The cumulative emissions per unit area also increased. In particular, the cumulative emissions of industrial solid waste per $\mathrm{km}^{2}$ increased from 1.94 to 60.23 million $\mathrm{kg}$. As industrial waste emissions were new pollutants produced each year, both cumulative pollution emissions and pollution exposure led to increased health risk. Risk to health increased with more pollutants and pollution exposure. Furthermore, population density increased, although there was a small fluctuation before 2008. Thus, the environment was deteriorating while population increased. In other words, more and more people were exposed to an increasingly polluted environment.

\subsubsection{Variation Profile of Health Risks}

Pollution in Changzhou had conspicuous effects on health. Total mortality was $5.5 / 10^{3}$ in 2001 , but reached $7.0 / 10^{3}$ in 2015 . The number of cases and mortality from cancer increased markedly in the past decades in Changzhou according to the data gathered from published literature. The number of inpatient cases of cancer in Changzhou was 1995 in 2002, and reached 6649 in 2011 (Figure 4). The mortality from cancer in Changzhou was $208.98 / 10^{5}$ in 2011 and increased to $222.08 / 10^{5}$ in 2015 [33]. Mortality was $214 / 10^{5}$ in Wujin district in 2009 and increased to $242.6 / 10^{5}$ in 2014 [36]. This was higher than the mortality in the whole city. The mortality from cancer in Liyang county was the lowest, although it increased from $151.88 / 10^{5}$ in 2010 to $171.4 / 10^{5}$ in 2014 [37]. 


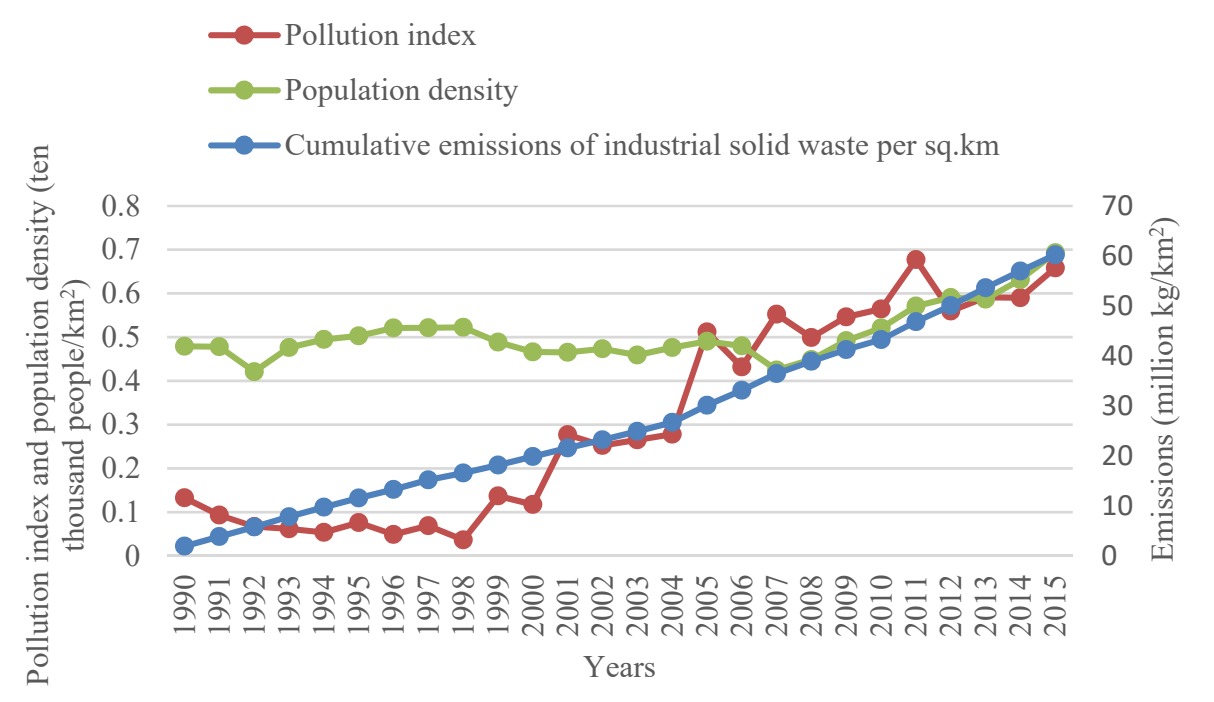

Figure 3. Time variations of environmental pollution and population density.

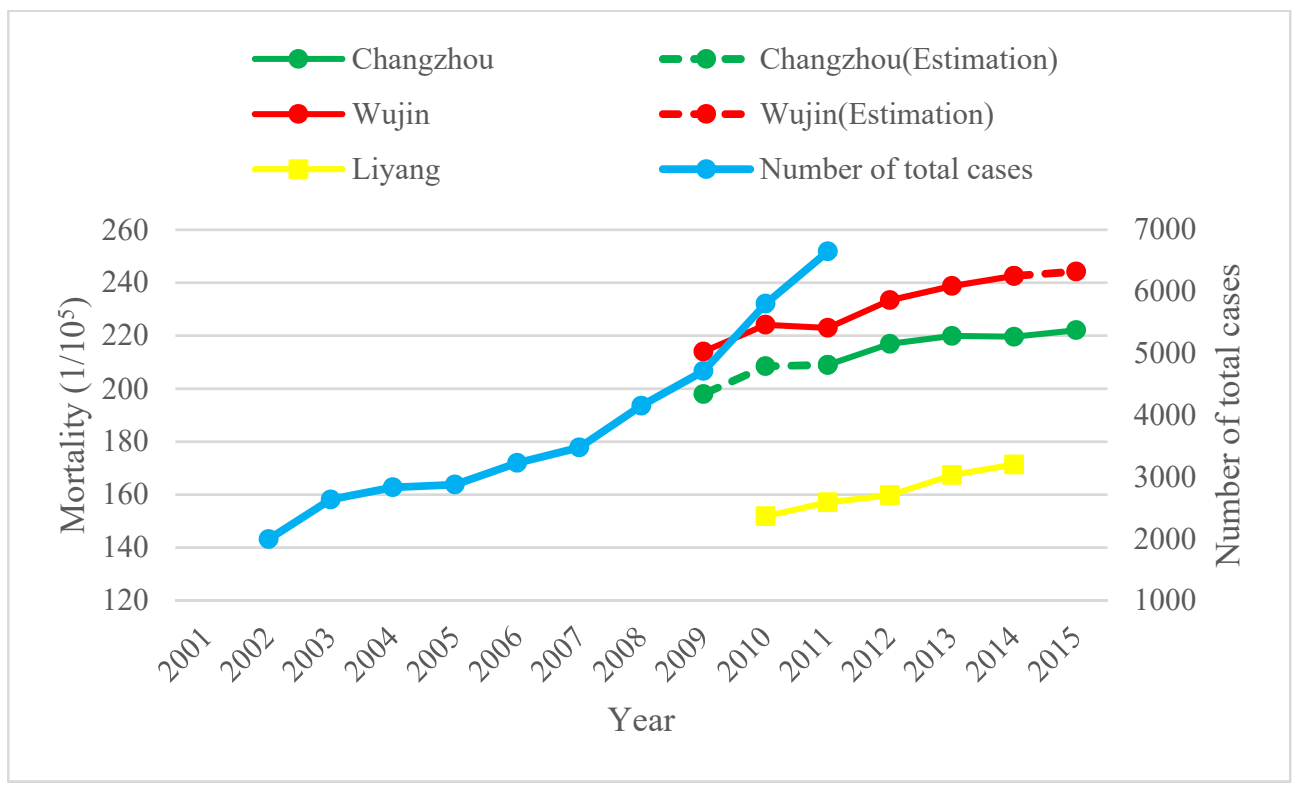

Figure 4. Time variations of the case number and mortality of cancers in Changzhou.

\subsection{Spatial Interpretation of Land Use and Environmental Health in Changzhou}

3.2.1. Bivariate Spatial Association of Urban Expansion and High-Polluting Industries

The area of construction land in 1995 and 2015 was interpreted based on remotesensing images (Figure 5a,b) to examine urban expansion in Changzhou. Construction land in 2014 totaled $1075.77 \mathrm{~km}^{2}$, a significant increase compared with that in $1995\left(618.63 \mathrm{~km}^{2}\right)$. There were a total of 2802 high-polluting enterprises located in the coverage of the construction land in 2015. The number of enterprises located in the coverage of the construction land in 1995 was 1150, and the number of enterprises located in the coverage of the increased construction land was 1404. Errors in image interpretation suggested that some enterprises were not located in the coverage of construction land. In general, the results indicated that high-polluting enterprises significantly increased along with urban expansion during the period from 1995 to 2015 (Figure 5c,d). 


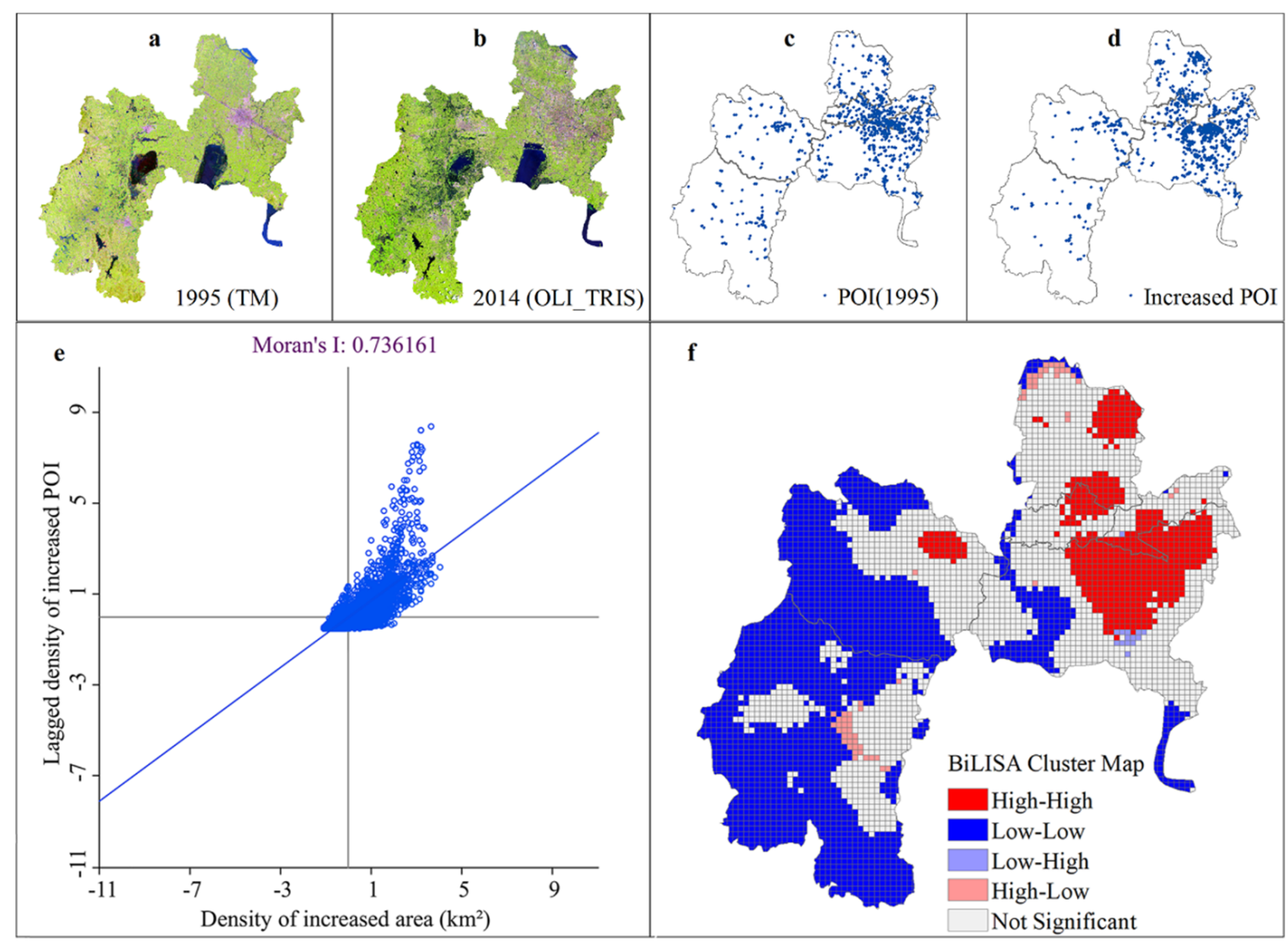

Figure 5. Spatial evolution of construction land and high-polluting industries from 1995 to 2014: (a,b) is remote-sensing image in 1995 and 2014 respectively; (c,d) is POI of high-polluting enterprise in 1995 and 2014 respectively; (e,f) is Mora's I scatter plot and LISA cluster map respectiavely.

We calculated the number of newly increased enterprises in each $1 \mathrm{~km} \times 1 \mathrm{~km}$ grid using point density analysis with ArcGIS software. Further, we examined the bivariate spatial associations between the area of newly increased construction land and the number of newly increased enterprises in each $1 \mathrm{~km} \times 1 \mathrm{~km}$ grid. The bivariate global Moran's I was approximately 0.74 , indicating that newly increased enterprises had a strong positive spatial association with newly increased construction land (Figure 5e). Figure $5 \mathrm{f}$ shows the bivariate local spatial clusters of newly increased enterprises and newly increased construction land. Clusters of High-High were mainly distributed in the suburban areas of Changzhou, including Wujin, Tianning, Zhonglou, and Xinbei. An exurb area in Xinbei and the northeast area of Jintan were also found with clusters of High-High, indicating that there were significantly high increases in both construction land and high-polluting enterprises. In contrast, rural areas far away from urban areas were found with significantly low increases in both construction land and high-polluting enterprises (clusters of Low-Low).

\subsubsection{Spatial Distribution of Environmental Health Events}

A series of environmental health events caused by environmental pollution occurred during the urbanization of Changzhou. These environmental health events were mainly scattered in 77 places, among which 11 places suffered the occurrence of cancers, according to web media reports. Most of these environmental health events $(62.67 \%)$ were distributed in the urban districts of Changzhou. Jintan also saw multiple occurrences of severe environmental health events. Field surveys and high-resolution image interpretation showed that all of the places that experienced environmental events were adjacent to high-polluting enterprises or brownfields. Several significant environmental health events and their locations are shown in Figure 6, revealing the spatial relationship between industrialized urban expansion and environmental health. Locations (1) and (2) show that high-polluting 
enterprises in the exurb area of Changzhou were correlated with the occurrence of cancer events. Xinbei first reported the occurrence of cancer events in 2003. In 2008, it had one of the highest rates of cancer. Reports indicated that 90 in 750 people were afflicted with cancer in Henshanqiao village in Wujin (location (2)) in March 2013. Location (3) shows that the high-polluting enterprises in the suburban areas of Changzhou caused residents to feel unwell frequently. (4) shows the location of a commercial residential building built on the site of several decommissioned chemical plants. (5) shows the location of student poisoning events at the Changzhou foreign language school. These generated a lot of press coverage in April 2016.

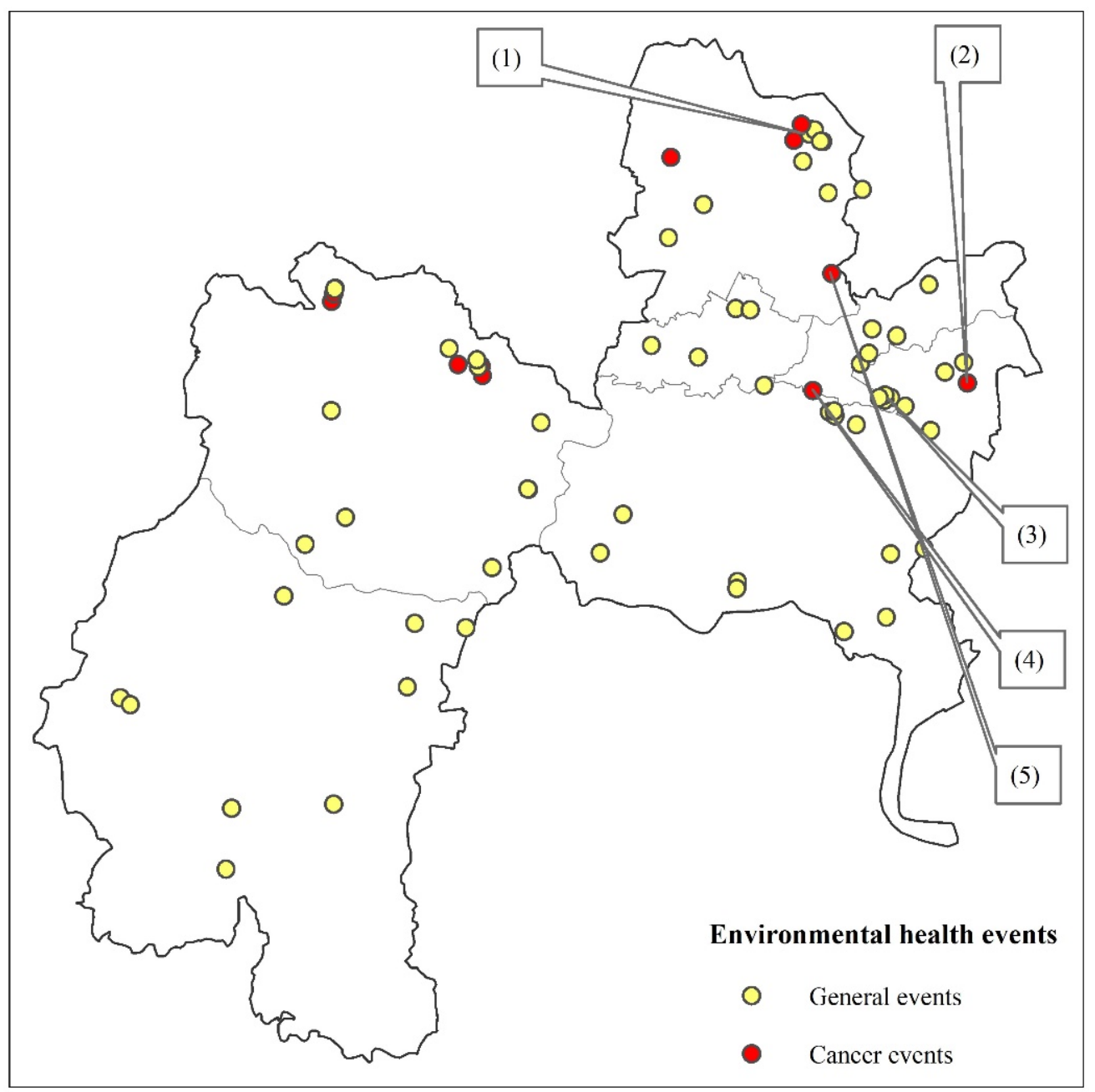

Figure 6. Locations with environmental health event reports. Note: the points do not represent accurate geographical coordinates of the events, but refer to the approximate locations and their adjacent regions according to the media reports; general events refer to the events which cause uncomfortableness or health ailments in humans, and cancer events refer to the events which are mainly related to cancer and cancer risks.

\subsection{Further Evidence of the Relationship between Land-Use Change and Environmental Health Risks}

Transformations in population, land use, and industry are essential features of urbanization. Thus, UR, CLA, and PHI were considered as proxy variables and were included as independent variables in the GAM model, to further verify the impact of urban expansion or urban land-use change on health risks. The results are shown in Table 2. UR and PHI were found to have a linear relationship with total mortality $(p<0.01)$, and CLA presented a nonlinear relationship with total mortality. The explained deviances and the 
determination coefficients were low (Dev $\left.<55 \% ; \mathrm{R}^{2}<0.50\right)$. However, UR, CLA, and PHI showed significant nonlinear relationships with the number of cancer cases $(p<0.001)$, and the models had good explanatory power and goodness of fit $\left(\operatorname{Dev}>95 \% ; \mathrm{R}^{2}<0.70\right)$. In addition, UR showed a linear relationship with the mortality of cancer, and CLA presented a nonlinear relationship with the mortality of cancer $(p<0.01)$. The models had good explanatory power and goodness of fit. PHI also showed a linear relationship with the mortality of cancer, but the model was non-significant and had poor explanatory power and goodness of fit $\left(p=0.379\right.$, adjusted $\left.R^{2}=-0.01\right)$.

Table 2. Results of the GAM model and its comparison with the SLR.

\begin{tabular}{|c|c|c|c|c|c|c|c|c|}
\hline \multirow{2}{*}{\multicolumn{2}{|c|}{ Pairs of Variables }} & \multicolumn{4}{|c|}{ GAM } & \multicolumn{3}{|c|}{ SLR } \\
\hline & & eDF & $\operatorname{Dev}(\%)$ & $p$ & $\begin{array}{c}\text { Adjusted } \\
\mathbf{R}^{2}\end{array}$ & $\beta$ & $p$ & $\mathbf{R}^{2}$ \\
\hline \multirow{3}{*}{ Total mortality } & UR & 1 & 48.4 & 0.0038 & 0.45 & 0.0413 & 0.0040 & 0.44 \\
\hline & CLA & 2.008 & 54.3 & 0.0198 & 0.47 & 0.0091 & 0.0215 & 0.29 \\
\hline & PHI & 1 & 44.3 & 0.0065 & 0.40 & 0.0822 & 0.0067 & 0.40 \\
\hline \multirow{3}{*}{$\begin{array}{l}\text { Number of } \\
\text { cancer cases }\end{array}$} & UR & 3.108 & 97.3 & $<0.001$ & 0.96 & 113.64 & $<0.001$ & 0.83 \\
\hline & CLA & 1.794 & 98.8 & $<0.001$ & 0.98 & 41.68 & $<0.001$ & 0.98 \\
\hline & PHI & 3.231 & 95.8 & $<0.001$ & 0.94 & 179.72 & $<0.001$ & 0.74 \\
\hline \multirow{3}{*}{$\begin{array}{c}\text { Cancer } \\
\text { mortality }\end{array}$} & UR & 1 & 95.9 & $<0.001$ & 0.95 & 1.909 & $<0.001$ & 0.95 \\
\hline & CLA & 1.811 & 92.1 & 0.0047 & 0.89 & 0.2381 & 0.0028 & 0.83 \\
\hline & PHI & 1 & 15.7 & 0.379 & -0.01 & -1.853 & -0.012 & 0.38 \\
\hline
\end{tabular}

Note: eDF donates the estimated degree of freedom, Dev donates the explained deviance, and $\beta$ is the regression coefficient of SLR.

The specific effects of these urbanization factors on health are shown in Figure 7. The total mortality grew linearly with increases in UR and PHI (Figure 7(a1,a3)), and generally showed nonlinear growth along with an increase in CLA (Figure 7(a2)). The number of cancer cases nonlinearly increased along with the three factors, but the nonlinear relationships were more significant between the number of cancer cases and UR and PHI (Figure 7(b1-b3)). The mortality of cancer exhibited linear growth and nonlinear growth with increased UR and CLA, respectively (Figure 7(b1,b2)). Figure 7(b3) shows that the mortality of cancer linearly decreased with an increase in PHI, but the explained deviance $(15.7 \%)$ and adjusted $R^{2}(-0.01)$ proved that the relationship was non-significant and unreliable. In addition, the simple linear regression (SLR) was calculated for comparison with the GAM. The estimated coefficient generally confirmed the relationships identified by the GAM, but the SLR showed disadvantages when the relationship between dependent and independent variables was complicated or nonlinear, because they yielded a lower $\mathrm{R}^{2}$ than that of the GAM (Table 2). 

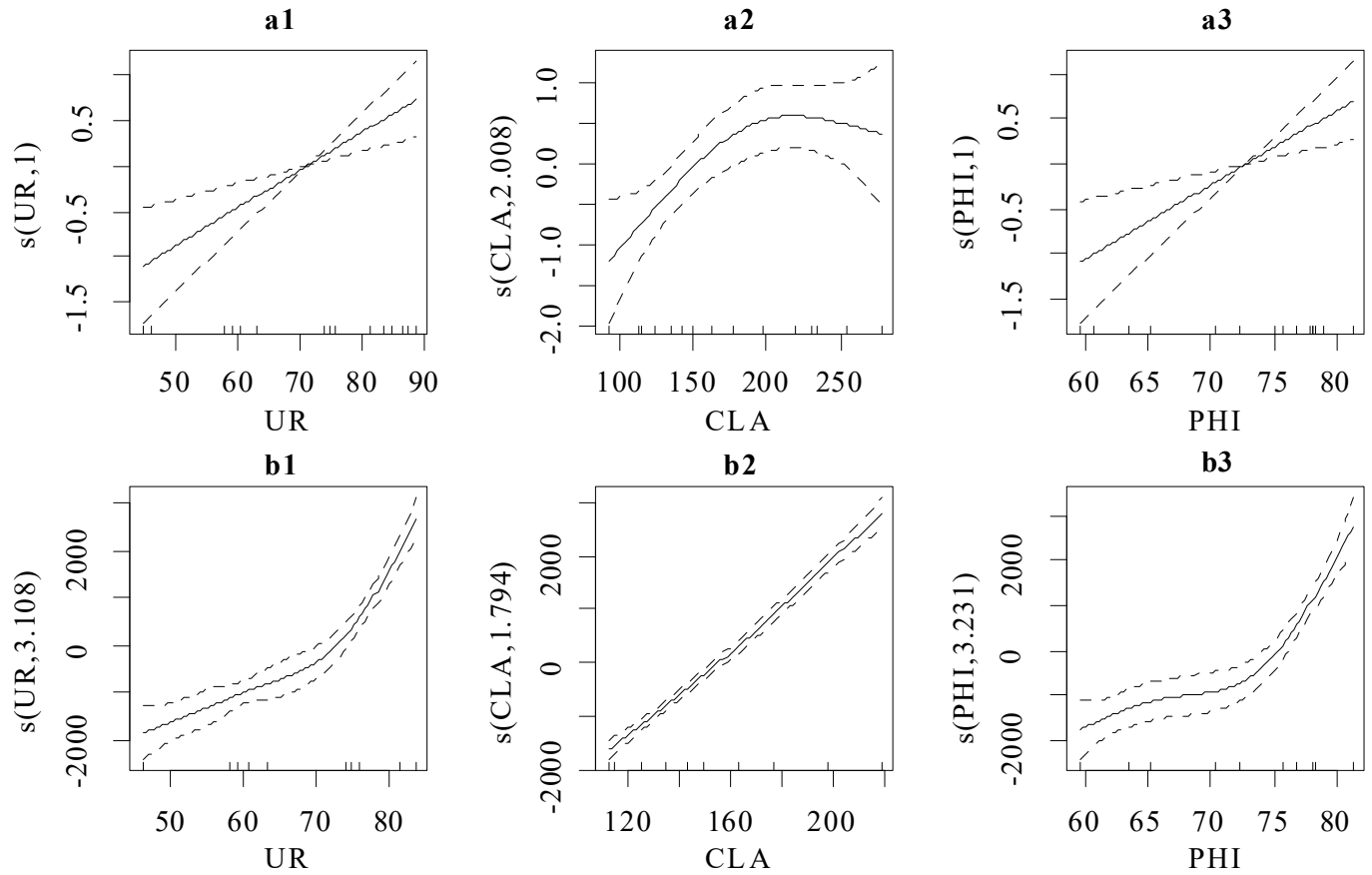

c1
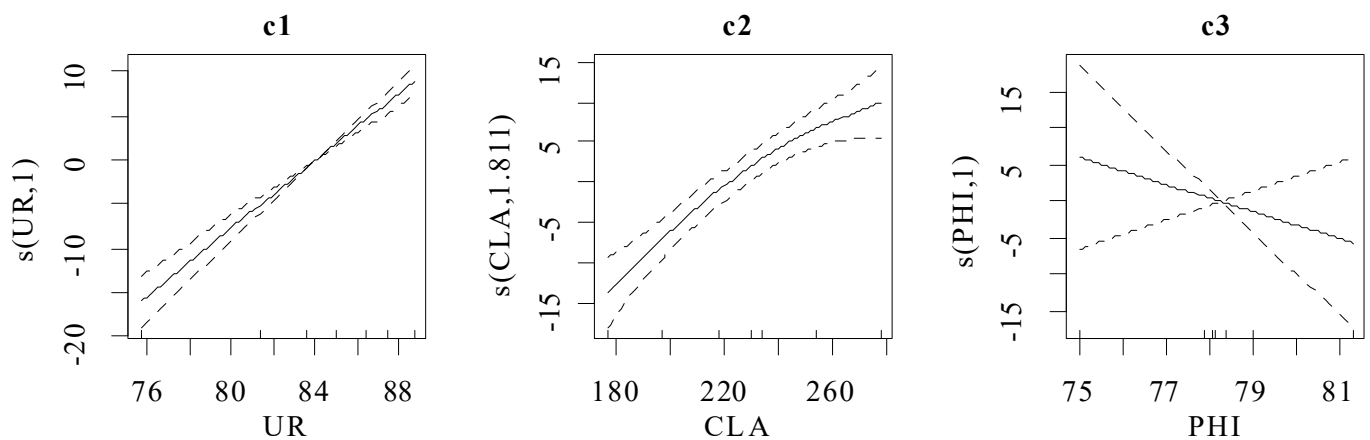

Figure 7. Effect of urbanization on health: (a1-a3), total mortality; (b1-b3), number of cancer cases; (c1-c3), mortality of cancer. Note: the vertical axis donates the fitted function value, the horizontal axis is the observations of the independent variable; solid line represents the fitted line (or curve) of the dependent variable, and the dotted line represents the confidence intervals.

\section{Discussion}

This paper interpreted the evolution of health risks associated with rapid urban expansion from a spatiotemporal perspective based on the case of Changzhou, China. The results showed that the pattern of Changzhou's urbanization is a typical case of industrial land expansion, which aggravated environmental pollution. Health risks in Changzhou tended to increase over time and with proximity to pollution. This kind of urbanization exposed the population to a polluted environment, and was related to increased health risks and the frequent occurrence of environmental health events.

With rapid urbanization, urban residents face decreasing environmental benefits, and even suffer a poisoned environment when pollutant emissions proliferate in the urban space. Furthermore, the development of industry increases pollution sources and extends the spatial distribution of pollutants, especially with people living close to past or current industrial sites [29,41-43]. In general, industrial urbanization exposes an increasing number of people to a polluted environment, and long-term pollution exposure is related to increased health risks. The spatiotemporal perspective here adopted can help facilitate an understanding of the mechanism and spatiotemporal patterns of health risks, and risk assessments of environmental health.

High-resolution spatiotemporal data can mitigate uncertainties and bias in exposure assessments [44,45]. However, there are few monitoring platforms and databases for gath- 
ering spatiotemporal data on chronic non-communicable diseases and human mortality in China. The spatiotemporal discontinuity of environmental health events and privacy issues related to diseases caused by pollution present challenges for quantitative analyses of the relationship between land-use change and health. In our study, however, we collected multi-source data in an effort to explain this relationship. Our results showed that Changzhou's urbanization featured rapid development, rapid population growth, extensive urban land expansion, and industrialization dominated by heavy industry (Figure 2). Industrial waste emissions increased alongside increasing population levels in a worsening environment (Figure 3). Further, increases in the total death rate of the city's population, the number of cancer cases, and cancer mortality support the pattern of exacerbated health risks (Figure 4).

Increases in new construction land and high-polluting enterprises showed clusters of High-High in the inner suburban areas of Changzhou, an exurb area of Changzhou, and a suburban area in Jintan district, indicating that urban expansion presented a high spatial association with variations in enterprises of high-polluting industries (Figure 5e,f). The spatial distribution of environmental health events presented spatial adjacency with enterprises of high-polluting industries or brownfields (Figure 6). This indicated that urbanization exposed people to polluted environments and caused environmental health events. In particular, cancer events in Xinbei and Wujin were both adjacent to highpolluting enterprises.

The results of the GAM analysis also revealed that rapid urban land expansion resulted in increased health risks. The total mortality and the number of cancer cases generally increased along with the development of urbanization factors, including population, land use, and industry. The variation in total mortality showed a nonlinear response to the construction land area, and even transformed when the construction land area reached $200 \mathrm{~km}^{2}$ (Figure 7(a2)). Larger construction land or urban space may disperse concentrated populations to avoid gathering around pollution sources, and restrain increases in environmental health risks. Increases in the urbanization rate and construction land area were also found to be related to increases in cancer mortality. According to the data on health risks, these increased along with the development of urbanization.

There were differences in the time ranges for several kinds of data. Changzhou's administrative division has changed since 2002. Thus, we selected the period from 2003-2018 when calculating the urbanization rate. The total population and industrial waste emissions are measured for the entire city, and thus cannot be divided into administrative division. Therefore, we selected a longer time range. There were no long-term data on cancer because monitoring platforms on chronic non-communicable diseases were only recently introduced in China. Thus, we extrapolated relevant health data and events from literature and media coverage. When we conducted statistical analyses, mainly in the GAM model, the common time range was used to treat the discrepancies.

Our results have some policy implications. First, more attention should be paid to environmental health. The government should inspect, analyze, and transform current urbanization patterns with rapid industrial land expansion. Urbanization plans should consider the increase in population, industrial development, and urban expansion, and environmental assessments are needed for redevelopment plans and new extensions of land. Second, monitoring databases and platforms for land pollution and public health are urgently needed and should be accessible to the public. Complete real-time data can help interpret the dynamics of pollution and health and assist with risk warning. Besides, environmental impact assessment should be paid sufficient attention to support urban functional zoning in future. Strict and scientific criteria related to environmental health should be set and strictly enforced, including safe distances between urban land space and industrial sites or brownfield land, and safe pollutant emission standards. Precaution is more important than governance. 


\section{Conclusions}

This paper investigated the evolution of health risks with rapid urban expansion from a spatiotemporal perspective. The results help clarify the relationship between health risks and land-use change during the process of urbanization. Urban expansion, massive growth in industry, a rapid increase in population, and large-scale urban land expansion expose populations in polluted environments to environmental health risks. Our study confirmed that inner suburbs close to decommissioned industrial sites and outer suburbs close to industrial parks are generally high-risk areas in cities with industrial urbanization. Multifaceted changes, such as land use change, urban environment change, and residents' lifestyle change during urbanization process, may independently or synergistically affect health. More attentions on the influences of these factors and the dominant factor that influences health, and their regional differences are recommended in future studies. Accurate spatial assessment and pre-warning for health risks also deserve further investigation.

Author Contributions: C.Y. conceived and initiated the study, J.X. provided useful suggestions. D.Y. mainly undertook statistical analysis and manuscript writing. All authors have read and agreed to the published version of the manuscript.

Funding: This study was sponsored by the National Natural Science Foundation of China (Grant No.41571138) and Natural Science Foundation of Henan (No. 202300410076), China.

Data Availability Statement: The data presented in this study are available on request from the corresponding author. The raw data are not publicly available, except memberships.

Conflicts of Interest: The authors declare that they have no competing interests.

\section{References}

1. Talukder, S.; Capon, A.; Nath, D.; Kolb, A.; Jahan, S.; Boufford, J. Urban health in the post-2015 agenda. Lancet 2015, $385,769$. [CrossRef]

2. Gong, P.; Liang, S.; Carlton, E.J.; Jiang, Q.; Wu, J.; Wang, L.; Remais, J.V. Urbanisation and health in China. Lancet 2012, 379, 843-852. [CrossRef]

3. Changzhou Staticstical Yearbook 2019. Available online: http://tongji.cnki.net/ (accessed on 18 November 2020).

4. Bloom, D.E.; Canning, D.; Fink, G. Urbanization and the Wealth of Nations. Science 2008, 319, 772-775. [CrossRef]

5. Alirol, E.; Getaz, L.; Stoll, B.; Chappuis, F.; Loutan, L. Urbanisation and infectious diseases in a globalised world. Lancet Infect. Dis. 2011, 11, 131-141. [CrossRef]

6. Song, W.; Liu, M. Farmland Conversion Decreases Regional and National Land Quality in China. Land Degrad. Dev. 2017, 28, 459-471. [CrossRef]

7. Zhou, C.; Li, S.; Wang, S. Examining the impacts of urban form on air pollution in developing countries: A case study of China's megacities. Int. J. Environ. Res. Public Health 2018, 15, 1565. [CrossRef]

8. Yang, H.; Huang, X.; Thompson, J.R.; Flower, R.J. China's Soil Pollution: Urban Brownfields. Science 2014, 344, 691-692. [CrossRef]

9. Bian, J.; Ren, H.; Liu, P.; Zhang, Y. Sustainable Urbanization Performance Evaluation Based on "Origin" and "Modernization" Perspectives: A Case Study of Chongqing, China. Int. J. Environ. Res. Public Health 2018, 15, 1714. [CrossRef]

10. Wang, D.; Kwan, M. Selected studies on urban development issues in China: Introduction. Urban Geogr. 2017, 38, 360-362. [CrossRef]

11. Cheng, F.; Geertman, S.; Kuffer, M.; Zhan, Q. An integrative methodology to improve brownfield redevelopment planning in Chinese cities: A case study of Futian, Shenzhen. Comput. Environ. Urban Syst. 2011, 35, 388-398. [CrossRef]

12. Liu, Y.; van Oort, F.; Geertman, S.; Lin, Y. Institutional determinants of brownfield formation in Chinese cities and urban villages. Habitat Int. 2014, 44, 72-78. [CrossRef]

13. Zhu, Y.G.; Ioannidis, J.P.; Li, H.; Jones, K.C.; Martin, F.L. Understanding and harnessing the health effects of rapid urbanization in China. Environ. Sci. Technol. 2011, 45, 5099-5104. [CrossRef]

14. Thompson, A.L.; Houck, K.M.; Adair, L.; Gordon-Larsen, P.; Popkin, B. Multilevel examination of the association of urbanization with inflammation in Chinese adults. Health Place 2014, 28, 177-186. [CrossRef]

15. Whiting, D.; Unwin, N. Cities, urbanization and health. Int. J. Epidemiol. 2008, 38, 1737-1742. [CrossRef] [PubMed]

16. Vlahov, D.; Freudenberg, N.; Proietti, F.; Ompad, D.; Quinn, A.; Nandi, V.; Galea, S. Urban as a determinant of health. J. Urban Health 2007, 84, 16-26. [CrossRef]

17. Kwan, M.P.; Wang, J.; Tyburski, M.; Epstein, D.H.; Kowalczyk, W.J.; Preston, K.L. Uncertainties in the geographic context of health behaviors: A study of substance users' exposure to psychosocial stress using GPS data. Int. J. Geogr. Inf. Sci. 2018, 33, 1176-1195. [CrossRef] 
18. De Hollander, A.E.M.; Staatsen, B.A.M. Health, environment and quality of life: An epidemiological perspective on urban development. Landsc. Urban Plan 2003, 65, 53-62. [CrossRef]

19. Zhang, J.; Mauzerall, D.L.; Zhu, T.; Liang, S.; Ezzati, M.; Remais, J.V. Environmental health in China: Progress towards clean air and safe water. Lancet 2010, 375, 1110-1119. [CrossRef]

20. Ren, W.; Xue, B.; Geng, Y.; Sun, L.; Ma, Z.; Zhang, Y.; Mitchell, B.; Zhang, L. Inventorying heavy metal pollution in redeveloped brownfield and its policy contribution: Case study from Tiexi District, Shenyang, China. Land Use Policy 2014, 38, 138-146. [CrossRef]

21. Raymond, C.M.; Gottwald, S.; Kuoppa, J.; Kyttä, M. Integrating multiple elements of environmental justice into urban blue space planning using public participation geographic information systems. Landsc. Urban Plan 2016, 153, 198-208. [CrossRef]

22. Li, P.; Wu, J.; Qian, H.; Lyu, X.; Liu, H. Origin and assessment of groundwater pollution and associated health risk: A case study in an industrial park, northwest China. Environ. Geochem. Health 2014, 36, 693-712. [CrossRef] [PubMed]

23. Li, D.; Zhang, C.; Pizzol, L.; Critto, A.; Zhang, H.; Lv, S.; Marcomini, A. Regional risk assessment approaches to land planning for industrial polluted areas in China: The Hulunbeier region case study. Environ. Int. 2014, 65, 16-32. [CrossRef] [PubMed]

24. Hou, D.; Li, F. Complexities Surrounding China's Soil Action Plan. Land Degrad. Dev. 2017, 28, 2315-2320. [CrossRef]

25. Li, F.; Qiu, Z.; Zhang, J.; Liu, W.; Liu, C.; Zeng, G. Investigation, pollution mapping and simulative leakage health risk assessment for heavy metals and metalloids in groundwater from a typical brownfield, middle China. Int. J. Environ. Res. Public Health 2017, 14, 768. [CrossRef]

26. Cabral Pinto, M.M.S.; Silva, M.M.V.; Ferreira da Silva, E.A.; Marinho-Reis, A.P. The cancer and non-cancer risk of Santiago island (Cape Verde) population due to totential toxic elements exposure from soils. Geosciences 2017, 7, 78. [CrossRef]

27. Lu, Y.; Song, S.; Wang, R.; Liu, Z.; Meng, J.; Sweetman, A.J.; Jenkins, A.; Ferrier, R.C.; Li, H.; Luo, W.; et al. Impacts of soil and water pollution on food safety and health risks in China. Environ. Int. 2015, 77, 5-15. [CrossRef]

28. Yousaf, B.; Liu, G.; Abbas, Q.; Wang, R.; Imtiaz, M.; Zia-ur-Rehman, M. Investigating the uptake and acquisition of potentially toxic elements in plants and health risks associated with the addition of fresh biowaste amendments to industrially contaminated soil. Land Degrad. Dev. 2017, 28, 2596-2607. [CrossRef]

29. Zhao, L.; Xu, Y.; Hou, H.; Shangguan, Y.; Li, F. Source identification and health risk assessment of metals in urban soils around the Tanggu chemical industrial district, Tianjin, China. Sci. Total Environ. 2014, 468-469, 654-662. [CrossRef]

30. Li, X.; Song, J.; Lin, T.; Dixon, J.; Zhang, G.; Ye, H. Urbanization and health in China, thinking at the national, local and individual levels. Environ. Health 2016, 15, 32. [CrossRef]

31. MEP; NDRC; MWR. Planning for the Prevention and Control of Water Pollution in Key River Basins (2016-2020); Minstry of Ecology and Environment of the People's Public of China: Beijing, China, 2017; pp. 3-199. Available online: http:/ /www.mee.gov.cn/ $\mathrm{gkml} / \mathrm{hbb} / \mathrm{bwj} / 201710 / \mathrm{t20171027} 4$ 24176.htm (accessed on 18 November 2020).

32. $\mathrm{Bu}, \mathrm{J} . ;$ Suo, L. Incidence trend of malignant tumor from inpatient. Chin. J. PHM Dec. 2013, 29, 807. (In Chinese)

33. Dong, H.; Yao, Y.; Yao, X. Death causes and life lost from maligant tumor among residents in Changzhou city from 2011 to 2015. Mod. Prev. Med. 2017, 44, 2512-2516. (In Chinese)

34. Wang, J.; Zhang, W.; Zhang, Y. Analysis of the Death Features of Malignant Tumor Patients in Tianning District of Changzhou. Occup. Health 2006, 22, 724-726. (In Chinese)

35. Shang, F.; Yu, R. Analysis on epidemic and death situation of malignant tumor among residents of Tianning District of Changzhou city from 2011-2013. Occup. Health 2015, 31, 2939-2942. (In Chinese)

36. Shi, S.; Xu, M.; Qiang, D. Analysis on death situation and life lost of malignant tumor among residents of Wujin District of Changzhou city from 2009-2014. Jiangsu J. Prev. Med. 2017, 28, 58-60. (In Chinese)

37. Zheng, G. Malignant Tumor Death Analysis of Liyang City Residents in 2010-2014. China Health Stand. Manag. 2016, $27,6-7$. (In Chinese)

38. Lee, S.-I. Developing a bivariate spatial association measure: An integration of Pearson's r and Moran's I. J. Geogr. Syst. 2001, 3, 369-385. [CrossRef]

39. Anselin, L.; Syabri, I.; Smirnov, O. Visualizing multivariate spatial correlation with dynamically linked windows. In Proceedings of the CSISS Workshop on New Tools for Spatial Data Analysis, Santa Barbara, CA, USA, 24-28 June 2002.

40. Song, Y.Z.; Yang, H.L.; Peng, J.H.; Song, Y.R.; Sun, Q.; Li, Y. Estimating PM2.5 concentrations in Xi'an City using a generalized additive model with multi-source monitoring data. PLOS ONE 2015, 10, e0142149. [CrossRef]

41. Bambra, C.; Cairns, J.M.; Kasim, A.; Smith, J.; Robertson, S.; Copeland, A.; Johnson, K. This divided land: An examination of regional inequalities in exposure to brownfield land and the association with morbidity and mortality in England. Health Place 2015, 34, 257-269. [CrossRef]

42. Silbergeld, E.K. Managing hazards in place: The risks of residual risks. Environ. Res. 2017, 158, 806-811. [CrossRef]

43. Liu, Z.; Lu, Y.; Wang, T.; Wang, P.; Li, Q.; Johnson, A.C.; Sarvajayakesavalu, S.; Sweetman, A.J. Risk assessment and source identification of perfluoroalkyl acids in surface and ground water: Spatial distribution around a mega-fluorochemical industrial park, China. Environ. Int. 2016, 91, 69-77. [CrossRef]

44. Kwan, M.P. The Limits of the Neighborhood Effect: Contextual Uncertainties in Geographic, Environmental Health, and Social Science Research. Ann. Am. Assoc. Geogr. 2018, 108, 1482-1490. [CrossRef]

45. Yang, D.; Lu, D.; Xu, J.; Ye, C.; Zhao, J.; Tian, G.; Wang, X.; Zhu, N. Predicting spatio-temporal concentrations of PM2.5 using land use and meteorological data in Yangtze River Delta, China. Stoch. Environ. Res. Risk Assess. 2018, 32, 2445-2456. [CrossRef] 